\title{
DNA Damage Caused by Ionizing Radiation in Embryonic Diploid Fibroblasts WI-38 Induces Both Apoptosis and Senescence
}

\author{
J. CMIELOVÁ ${ }^{1}$, R. HAVELEK ${ }^{1}$, A. JIROUTOVÁ ${ }^{1}$, R. KOHLEROVÁ ${ }^{1}$, M. SEIFRTOVÁ ${ }^{1}$, \\ D. MUTHNÁ ${ }^{1}$, J. VÁVROVÁ ${ }^{2}$, M. ŘEZÁČOVÁ ${ }^{1}$
}

${ }^{1}$ Department of Medical Biochemistry, Faculty of Medicine in Hradec Králové, Charles University in Prague, Czech Republic, ${ }^{2}$ Department of Radiobiology, Faculty of Military Health Sciences Hradec Králové, University of Defence Brno, Czech Republic

Received September 13, 2010

Accepted January 6, 2011

On-line May 16, 2011

\begin{abstract}
Summary
Cellular response to ionizing radiation-induced damage depends on the cell type and the ability to repair DNA damage. Some types of cells undergo apoptosis, whereas others induce a permanent cell cycle arrest and do not proliferate. Our study demonstrates two types of response of embryonic diploid fibroblasts WI-38 to ionizing radiation. In the WI-38 cells p53 is activated, protein p21 increases, but the cells are arrested in G2 phase of cell cycle. Some of the cells die by apoptosis, but in remaining viable cells $\mathrm{p} 16$ increases, senescence associated DNAdamage foci occur, and senescence-associated betagalactosidase activity increases, which indicate stress-induced premature senescence.
\end{abstract}

\section{Key words}

DNA damage $\bullet$ Ionizing radiation $\bullet$ Senescence $\bullet$ Stem cells

\section{Corresponding author}

J. Cmielová, Faculty of Medicine in Hradec Králové, Charles University in Prague, Šimkova 870, 50038 Hradec Králové 1, Czech Republic. E-mail: cmielovaj@lfhk.cuni.cz

\section{Introduction}

Radiotherapy is a crucial method of treatment of solid tumors. The goal of radiotherapeutical irradiation is tumor eradication, while maintaining integrity of healthy tissue. Fibroblasts are relatively quiescent and long living cells in almost all adult tissues and their radiosensitivity determines a baseline for therapeutical irradiation at maximum biologically effective doses. While in hematopoietic, lymphoid and germ cells the main response to irradiation is induction of apoptosis, in many solid tumors, fibroblasts and epithelial cells radiationinduced apoptosis is not convincingly proved. It is possible that the main mechanism of response of these tissues to irradiation is not apoptosis, but induction of socalled stress-induced premature senescence, SIPS.

In reaction to DNA damage an interconnected network of signaling is activated, and results in damage repair, temporary or permanent cell cycle arrest or cell death. The classic DNA-damage response pathway is initiated by activation of kinase ATM, which phosphorylates many substrates, among them transcription factor protein $\mathrm{p} 53$. Tumor suppressor $\mathrm{p} 53$ is a protein, which responds to various types of genotoxic stress, and is involved in induction of cell cycle arrest, apoptosis, senescence, DNA repair or changes in metabolism. Among others, protein p53 controls the expression of protein $\mathrm{p} 21^{\mathrm{Cip} 1 / \text { Waf1 }}$, product of the CDKN1A (inhibitor of cyclindependent kinase 1A) gene, which blocks the activity of cyclin dependent kinases and regulates progression of cell cycle in G1/S checkpoint (Ljungman 2000, Bringhold and Serrano 2000) and G2/M checkpoint (Taylor and Stark 2001). The arrest of the cell-cycle allows time for DNA damage repair. If the repair is unsuccessful, the cells are removed by apoptosis, necrosis or their proliferation is permanently suppressed by initiation of stress-induced premature senescence (SIPS).

The SIPS can be induced by UV radiation, ionizing radiation, hydrogen peroxide or 
chemotherapeutic agents (e.g. doxorubicin, cisplatin, camptothecin) (Suzuki and Boothman 2008). It was found, that ionizing radiation and chemotherapeutics used for treatment of cancer cause SIPS both in normal cells and in tumour cells (Raffetto et al. 2001). It was also found that some oncogenes can induce oncogene-induced senescence (Campisi et al. 2007). Several characteristics are in use for identification of senescent cells permanent cell cycle arrest, increased expression of cellcycle inhibitors (p21 $\left.1^{\text {Cip1/Wafl }}, \quad \mathrm{p} 16^{\text {INK4a }}, \mathrm{p} 15^{\text {INK4b }}\right)$, hypophosphorylation of $\mathrm{Rb}$ (retinoblastoma protein), activation of DNA-damage response, senescenceassociated secretory phenotype, morphologic changes, increase in senescence-associated $\beta$-galactosidase and formation of senescence-associated DNA-damage foci containing proteins that are associated with DNA damage response, e.g. $\gamma \mathrm{H} 2 \mathrm{AX}$ (Suzuki and Boothman 2008).

If the cells with not completely repaired DNA damage are not removed by apoptosis, but enter SIPS instead, it allows for selection of a resistant population, but it also has a significant downside as it creates a risk of developing a population of cells with dangerously damaged genome. Stem cells are nowadays intensively studied, because of their self-renewal capability, ability to produce a broad spectrum of cell types and high proliferation potential. Stem cells can be used in treatment of cancer, in bone marrow transplantation and peripheral blood stem cell transplantation for patients who had radiation treatment or high dose of chemotherapy. However, there is very little information about their reaction to DNA damage as a response to genotoxic stress, such as ionizing radiation used in the treatment of many cancer types.

Hematopoietic stem cells react to irradiation predominantly by apoptosis induction, but some senescence induction was also detected (Vávrová et al. 2002, Meng et al. 2003). Mesenchymal stem cells isolated from bone marrow do not die by apoptosis after irradiation, but they lose their ability to proliferate. The irradiation with the dose 2.5-15 Gy induces telomere shortening, cell division is stopped, but the cells are not destructed. The activity of senescence-associated $\beta$-galactosidase increases (Serakinci et al. 2007). Also mesenchymal stem cells isolated from dental pulp respond to irradiation primarily by induction of senescence (Muthna et al. 2010). It was found in the normal human embryonic diploid WI-38 fibroblasts, that busulfan (an alkylating agent leading to DNA damage) induces cellular senescence mainly associated with activation of extracellular signal-regulated kinase (Erk) and $\mathrm{p} 38$ MAPK (mitogen activated protein kinase). This cascade is independent on p53 activation (Probin et al. 2006).

The study of the reaction of stem cells to genotoxic stress is important for their safe usage, because they persist in organism for long time and can be the possible risk for the progression of population with damaged genome. The WI-38 human embryonic diploid fibroblasts are used as a model system in studies of stem cells. In this study we investigated the effect of ionizing radiation on WI-38 cells viability, proliferation, apoptosis and senescence induction, and changes in expression and phosphorylation status of proteins related to apoptosis and senescence.

\section{Materials and Methods}

\section{Cell culture}

WI-38 cells (human embryonic lung diploid fibroblasts) obtained from European Collection of Cell Cultures were cultured in $5 \% \mathrm{CO}_{2}$ atmosphere under $37{ }^{\circ} \mathrm{C}$ in Dulbecco's modified Eagle's medium (Sigma, USA) supplemented with $10 \%$ FCS (PAA, USA), $2 \%$ glutamine (Gibco, UK), penicillin/streptomycin (Gibco, UK) and $1 \%$ non-essential amino acids. Cells were dissociated and reseeded by using trypsin-EDTA (Gibco, UK). In all experiments, cells at early passages $(<10$ passages) were used and each of the passage reached approximately $70 \%$ confluence. Trypan blue staining was used for counting viable and non-viable cells.

\section{Irradiation procedure}

Exponentially-growing WI38 cells were suspended to $2.5 \times 10^{6}$ cells $/ \mathrm{ml}$ in complete medium. The aliquots were plated into $75 \mathrm{~cm}^{2}$ flasks (Nunc) or in chamber slides (Thermo Fisher Scientific) and after $24 \mathrm{~h}$ irradiated at room temperature using ${ }^{60} \mathrm{Co} \gamma$-ray source (Chisotron, Chirana, CZE) at the photon dose rate of $1 \mathrm{~Gy} / \mathrm{min}$ in the distance $1 \mathrm{~m}$ from the source. Cells were irradiated with the doses of 2, 6 and 20 Gy. Dosimetry was performed with an ionization chamber (Dosemeter PTW Unidos 1001, serial No. 11057, with ionization chamber PTW TM 313, serial No. 0012; RPD Inc., USA); the set was validated by Czech Metrology Institute (CMI) - Inspectorate for Ionising Radiation (IIR), protocol No. 9011-OL-U4124/2005). After irradiation, the flasks/chambers were placed in a $37^{\circ} \mathrm{C}$ incubator in a humidified atmosphere with $5 \% \mathrm{CO}_{2}$ and removed at 
various times following irradiation for analysis. Non irradiated controls were handled in parallel. The media was changed every 3 days after centrifugation, so the apoptotic floating cells were not discarded.

\section{Cell cycle analysis}

$1 \times 10^{6}$ of cells for each group were washed in cold PBS and fixed in $70 \%$ ethanol to permeabilize the cells. Than the cells were incubated for $5 \mathrm{~min}$ at room temperature in buffer $\left(192 \mathrm{ml} 0.2 \mathrm{~mol} / 1 \mathrm{Na}_{2} \mathrm{HPO}_{4}+8 \mathrm{ml}\right.$ $0.1 \mathrm{~mol} / 1$ citric acid, $\mathrm{pH} 7.8$ ) and then stained with $\mathrm{PI}$ in Vindelov's solution for 60 minutes at $37^{\circ} \mathrm{C}$. The DNA content was determined by flow cytometer Cytomics FC500 (Beckman Coulter) using $15 \mathrm{~mW}$ argon-ion laser with excitation capabilities at $488 \mathrm{~nm}$, and the total emission above $560 \mathrm{~nm}$ was recorded. List mode data were analyzed using Multicycle AV software (Phoenix Flow Systems, Inc.) and CXP (Beckman Coulter).

\section{Apoptosis detection}

For apoptosis detection Apoptest-FITC kit (DakoCytomation, CZE) was used according to manufactures instructions. Annexin $\mathrm{V}$ binds to phosphatidylserine at the cell surface in the presence of calcium ions. Propidium iodide is a marker of cell membrane permeability. The measurement was performed on Cyan ADP (Beckman Coulter, USA); list mode data were analyzed using Summit 4.3v software. $1 \times 10^{6}$ of cells were used for each group.

\section{Electrophoresis and western blotting}

After irradiation adherent WI-38 cells were collected and whole cell lysates were prepared for the analysis according to manufactures instructions (Cell Lysis Buffer, Cell Signaling Technology, Inc, Boston, MA). The content of protein was determined by using bicinchoninic acid assay (Sigma-Aldrich, St. Louis, MO). For the SDS-PAGE electrophoresis an equal amount of protein $(10 \mu \mathrm{g})$ was loaded into the gel. The proteins were then transferred to a PVDF membrane (Bio-Rad Laboratories s.r.o., CZE), the membrane was blocked in TBS with $5 \%$ non-fat dry milk and incubated with primary antibody (p53, p53_S392-Exbio, CZE; $\beta$-actin, p21 - Sigma-Aldrich, St. Louis, MO; p53_S15Calbiochem-Merck, CZE; mdm2_S166 - Cell Signaling Technology, Inc, Boston, MA) at $4{ }^{\circ} \mathrm{C}$ overnight. Then the membrane was incubated with polyclonal anti-mouse or anti-rabbit secondary antibody (DakoCytomation, $\mathrm{CZE}$ ). For the signal detection a chemiluminescence detection kit (Roche, CZE) was used.

\section{ELISA}

For quantitative assay of p21 PathScan Sandwich ELISA kit by Cell Signaling Technology was used according to manufactures instructions. The optical density (OD) measured at $450 \mathrm{~nm}$ was plotted against dose (in Gy).

Reverse transcription and real-time polymerase chain reaction

Total cellular RNA was isolated using RNeasy mini kit (Qiagen, Austria). One microgram of total cellular RNA was transcribed to cDNA with Multiscribe RT enzyme and random primers contained in the HighCapacity cDNA Reverse Transcription Kit (Applied Biosystems, USA). Gene expression was measured using TaqMan Gene Expression assay (Applied Biosystems), specifications are summarized in Table 1. CDKN2A generates several transcript variants. At least three alternatively spliced variants (NM_058195 variant 4, NM_058197variant 3, NM_000077 variant 1) encoding distinct proteins have been reported. For any additional information see www.appliedbiosystems.com.

cDNAs were quantified with TaqMan Gene Expression Assays and TaqMan Universal PCR Master Mix, using the 7500 Fast (Applied Biosystems, USA). The results were normalized to18S RNA.

Table 1. TaqMan Gene Expression assai.

\begin{tabular}{lll}
\hline Gene symbol & $\begin{array}{l}\text { Accession } \\
\text { number }\end{array}$ & Assay ID \\
\hline TP53 & NM_000546 & Hs00153349_m1 \\
$\begin{array}{l}\text { CDKN1A } \\
(\text { p21 })\end{array}$ & NM_078467 & Hs00153349_m1 \\
$\begin{array}{l}\text { CDKN2A } \\
\text { (p16) }\end{array}$ & NM_058195, & Hs00233365_m1 \\
& NM_058197, & \\
\hline
\end{tabular}

\section{Caspase activity assay}

For detection of caspase $3 / 7$, caspase 8 and caspase 9 activity Caspase-Glo Assays (Promega, USA) were used according to manufactures instruction. To measure the assays results Tecan Infinite 200 (Schoeller Instruments) was used. 


\section{Microscopy}

The cells were irradiated in chamber slides (Thermo Fisher Scientific). Activity of beta-galactosidase was detected by Senescence beta-galactosidase Staining Kit (Cell Signaling) according to manufactures instructions. For detection of vimentin and $\gamma \mathrm{H} 2 \mathrm{AX} 1 \times 10^{4}$ cells were irradiated, centrifugated, washed in PBS and fixed with paraformaldehyde for $10 \mathrm{~min}$ at room temperature, then washed in PBS. Cells were blocked in solution with $7 \% \mathrm{FCS}$ and $2 \% \mathrm{BSA}$ and immunostained with appropriate primary $\mathrm{Ab}$ (anti-Vimentin DakoCytomation, CZE; $\gamma \mathrm{H} 2 \mathrm{AX}-$ Cell Signaling Technology, Inc, Boston, MA; p16 - Sigma-Aldrich, St. Louis, MO) overnight at $4{ }^{\circ} \mathrm{C}$. The secondary antibody was applied to each slide (after their pre-incubation with $5.5 \%$ donkey serum in PBS for $30 \mathrm{~min}$ at room temperature) and incubation for $1 \mathrm{~h}$ in the dark was succeeded by washing ( $3 \times 5 \mathrm{~min})$ in PBS. The nuclei were counterstained by DAPI solution (Sigma, St. Louis, MO, USA), incubated 8 minutes, washed and fixed. Images were obtained by Nikkon Eclipse fluorescence microscope; the exposition time and dynamic range of camera in all channels were adjusted to the same values for all slides to obtain quantitatively comparable images.

\section{Comet assay}

DNA damage was measured using alkaline version of comet assay. Cells embedded in $1 \%$ agarose on microscope slides were lysed in $10 \mathrm{mM}$ Tris-buffered $2.5 \mathrm{M} \mathrm{NaCl}$ (pH 10.0) containing $1 \%$ Triton X 100, $100 \mathrm{mM}$ EDTA for 1 hour at $4{ }^{\circ} \mathrm{C}$. After a 40 minutes period of unwinding the electrophoresis was carried out at $25 \mathrm{~V}, 300 \mathrm{~mA}$, for $30 \mathrm{~min}$ at $4{ }^{\circ} \mathrm{C}$. Before microscopy examination the cells were stained with $2 \%$ ethidium bromide. At least 100 cells were accounted. The damage was classified into 3 categories, intact cells, damaged cells (40-70\% of DNA in the tail) and severely damaged cells (70-100\% of DNA in the tail).

\section{Results}

\section{Cell viability}

WI-38 cells $\left(1 \times 10^{6}\right)$ were irradiated with the doses of 2, 6 and 20 Gy and were counted after 3, 6 and 13 days. After 3 days cells in control group doubled, and kept proliferating during the whole experiment. The irradiation with the dose of 2 Gy inhibits proliferation until day 3 , but the cells remain viable (5\% of dead cells) and start proliferating again, and until day 6 they doubled their amount and kept their proliferative activity till day 13. Irradiation by the doses of 6 and 20 Gy causes with decrease in number of viable cells (day $3-7 \times 10^{5}$ in both groups, which deepened until day $13-5.9 \times 10^{5}$ after $6 \mathrm{~Gy}, 5.3 \times 10^{5}$ after $20 \mathrm{~Gy}$ ). After the irradiation with the doses 6 and 20 Gy the amount of dead cells increased in time, reaching $34 \%$ (6 Gy), resp. $44 \%$ (20 Gy) on day 13 .

\section{Comet assay}

The ionizing radiation induces massive DNA fragmentation (Fig. 1). Our results show that in control $94 \%$ of cells were intact. One hour post irradiation significant DNA damage was found in all irradiated samples: after the dose of 2 Gy $67 \%$ of cells were damaged (40-70\% DNA in comet tail) and $6 \%$ of cells severely damaged (70-100 \% DNA in comet tail). In cells irradiated with the doses 6 and 20 Gy significant DNA damage also occurred 1 hour after the irradiation - $14 \%$ resp. $33 \%$ of cells were damaged and $84 \%$ resp. $62 \%$ were severely damaged. After 24 hours post irradiation the cells repaired most of the damage and the percentage of damaged cells was low: $10 \%$ in $2 \mathrm{~Gy}, 10 \%$ in $6 \mathrm{~Gy}$, and $8 \%$ in 20 Gy were damaged and $4 \%$ in $2 \mathrm{~Gy}, 3 \%$ in $6 \mathrm{~Gy}$, and $6 \%$ in 20 severely damaged (Fig. 1B).
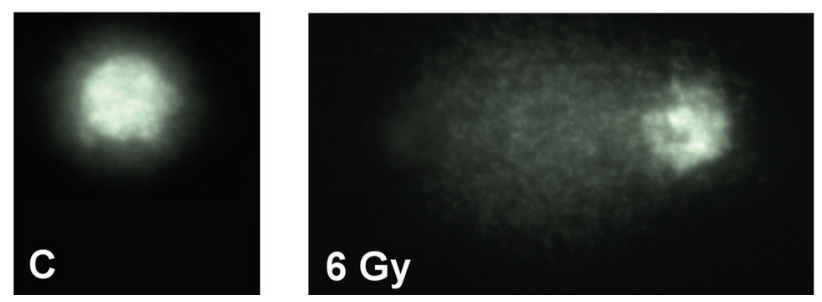

Fig. 1. DNA damage $1 \mathrm{~h}$ after the irradiation of WI-38 by comet assay. Sample results from the comet analysis of control cells and in cells $1 \mathrm{~h}$ after the irradiation with the dose of $6 \mathrm{~Gy}$.

Apoptosis induction, activation of caspases and morphologic changes

The irradiation induced moderate apoptosis after 6 days (10\% after 2 Gy, $14.4 \%$ after 6 Gy and $10.2 \%$ after $20 \mathrm{~Gy}$; control $7.5 \%$ ) (Fig. 2A).

We also determined the effect of irradiation of WI-38 with the doses 2, 6 and 20 Gy on the activity of caspases 3/7, 8 and 9 on 6 days post irradiation. There were no significant changes in caspases activity observed in day 1 and 3 (data not shown). In 6 days the activity of caspases $3 / 7,8$ and 9 was slightly but significantly increased after the irradiation with the doses of 6 and 
A
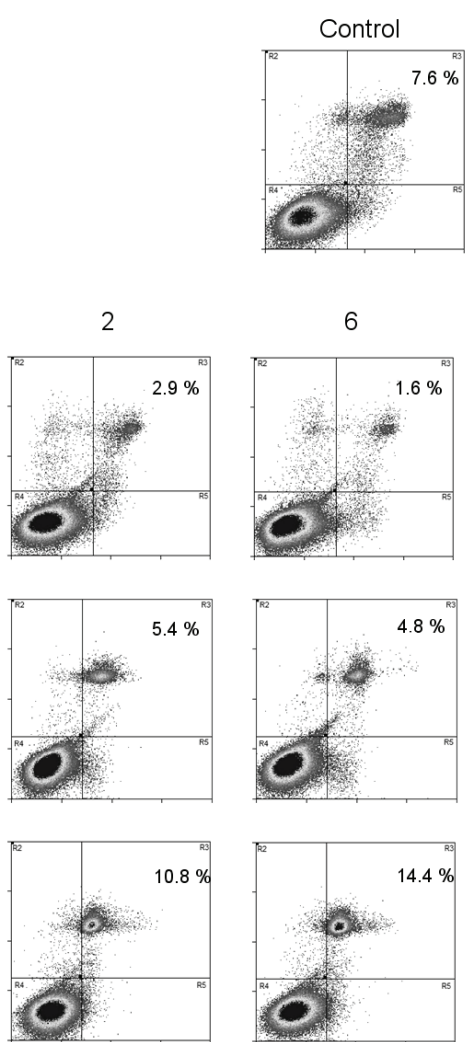

6
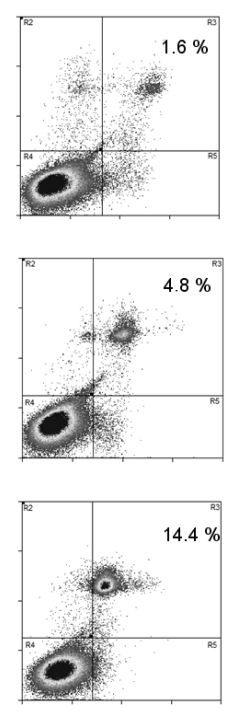

Annexin V - FITC
B
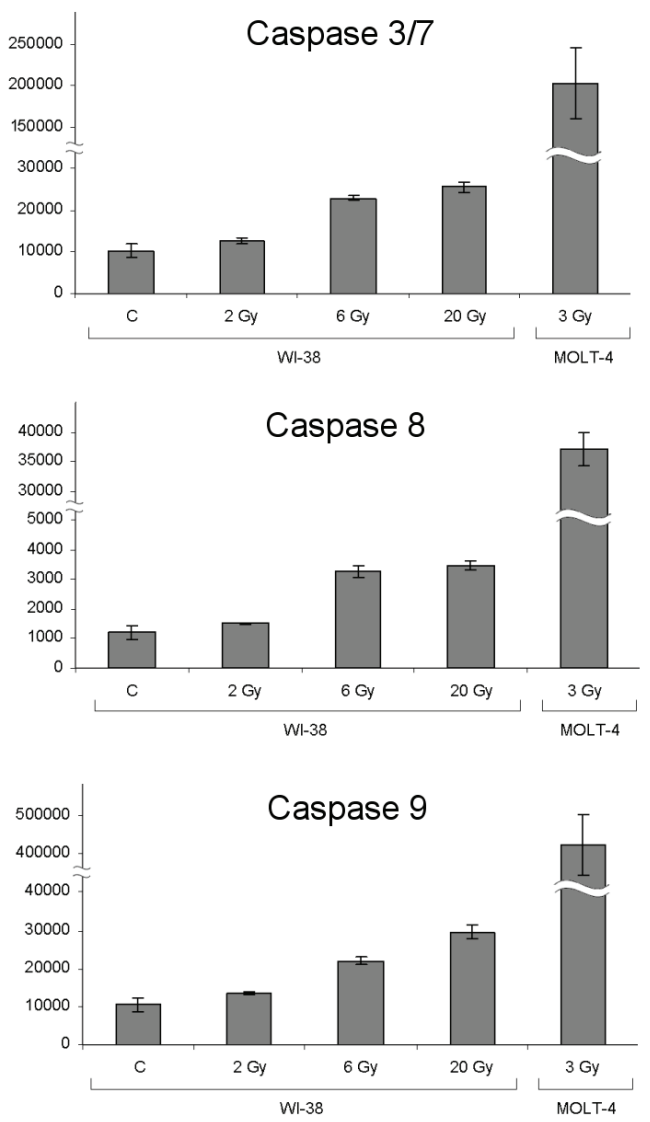

Fig. 2. The effect of irradiation of WI-38 cells with the doses of 2, 6 and 20 Gy on the apoptosis during 6 days after irradiation. A: Apoptosis detection was determined by Annexin $\mathrm{V}$ and propidium iodide staining. Apoptosis was messured 1, 3 and 6 days after the irradiation with the doses of 2,6 and $13 \mathrm{~Gy}$. B: Activity of caspases 3, 8 and 9 was determined 6 days after irradiation with the doses of 2, 6 and $20 \mathrm{~Gy}$ in WI-38 cells and after the irradiation with the dose of 3 Gy in MOLT-4 cells as a positive control.

20 Gy $(\mathrm{p}<0.05)$ (Fig. 2B). When compared to caspase activation in T-leukemic MOLT-4 cells $24 \mathrm{~h}$ after irradiation with the dose of 3 Gy (100\% apoptosis induction), the caspase activity in irradiated WI-38 cells was approximately 10 times lower.

For detection of morphologic changes which are contributed to apoptosis the cell nuclei were stained with DAPI. Our results show no changes in nuclear morphology of adherent cells irradiated with the dose of 20 Gy during the experiment (Fig. 5B).

\section{Ionizing radiation induces cell cycle arrest}

We used cell cycle analysis by flow cytometry to determine possible cell cycle arrest after irradiation. The irradiation with the dose of 2 Gy has only small effect on cell cycle distribution with slight accumulation of cells in G2 phase (26\% in day $1,22 \%$ in day 3, $21 \%$ in day 6 ; control $19 \%$ in G2 phase) and decrease in number of cells in S phase (4\% in day $1,6 \%$ in day 3, $9 \%$ in day 6 ; control $13 \%$ in $\mathrm{S}$ phase), both manifesting mainly on day 1 (Fig. 3). After the irradiation with the doses of 6 as well as 20 Gy significant number of cells are arrested in $\mathrm{G} 2$ phase as early as first day after irradiation, the number of arrested cells decreases in time (40\% resp. $42 \%$ in day $1,30 \%$ resp. $36 \%$ in day $3,11 \%$ resp. $28 \%$ in day 6; control 19\%) (Fig. 3).

\section{Protein 553 and its phosphorylations}

Ionizing radiation caused significant upregulation of p53. Four hours after the irradiation the level of protein p53 increases and reaches its maximum. First day post irradiation the level is decreased, than increases in day 3 again and is rapidly decreasing in time. Phosphorylation of p53 at serine 15 occurs also already 4 hours after irradiation and its level is decreased back to control level in 6 days. Maximal phosphorylation at serine 392 reaches its maximum 4 hours after irradiation as well and is decreased back to control level in 1 day. The negative regulator of the protein p53 mdm2 is upregulated and activated by phosphorylation of serine 166. Mdm2 protein and its phosphorylation on serine 166 are increased 4 hours after the irradiation (Fig. 4A). 
Control
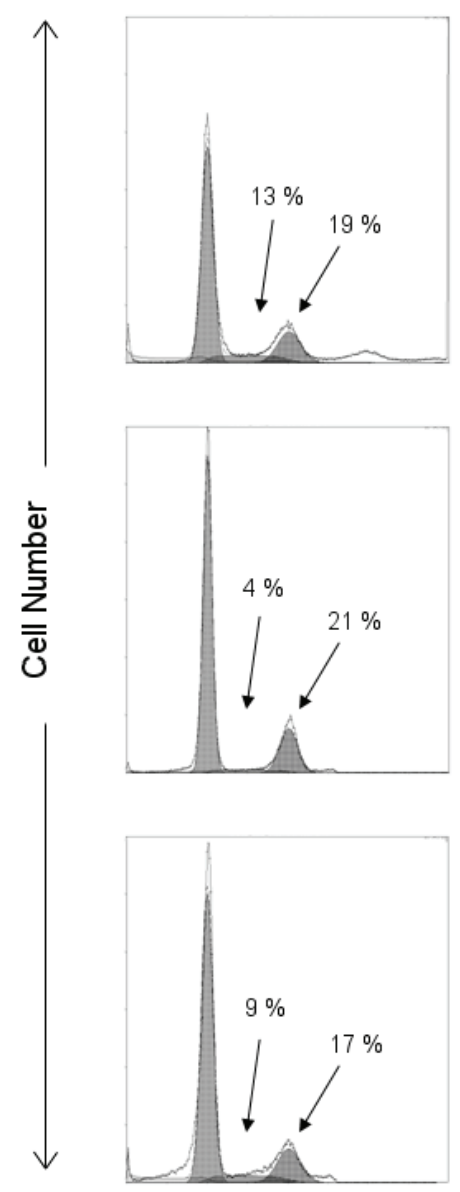

2
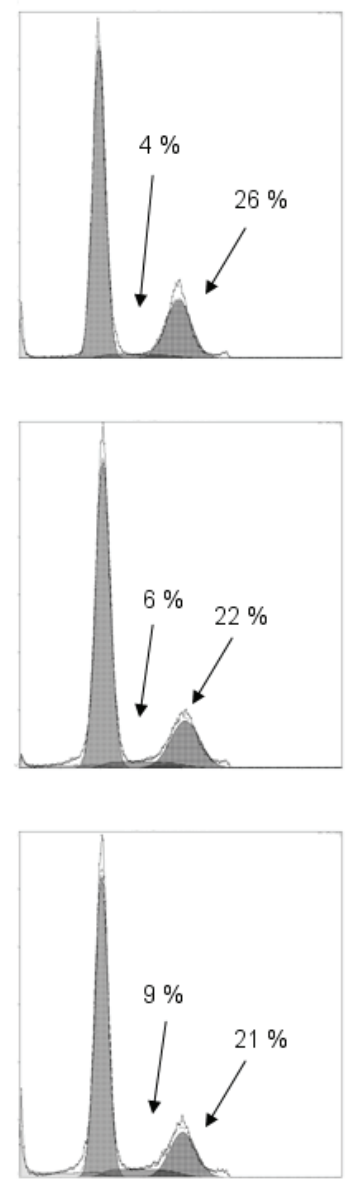

6
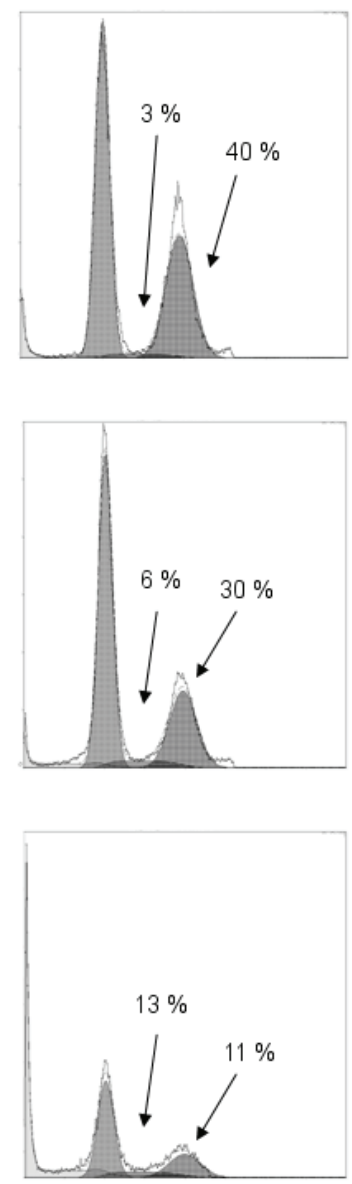

20 Gy

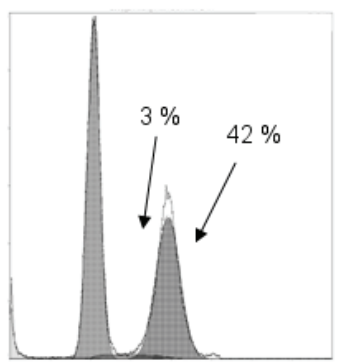

Day 1

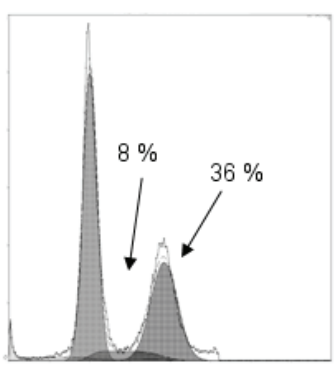

Day 3

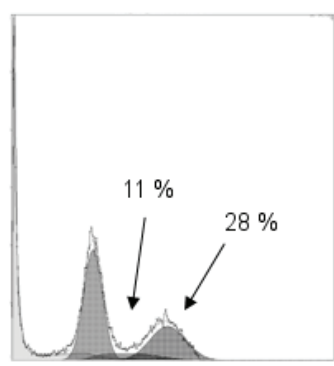

Day 6

\section{DNA content}

Fig. 3. The effects of irradiation on the distribution of WI-38 cells in the cell cycle. Cell cycle distribution was measured using flowcytometric detection of DNA content in the cells. Cell cycle was analysed 1, 3 and 6 days after the irradiation with the doses of 2, 6, and 20 Gy.

Changes in expression of proteins p21 and senescence induction

Ionizing radiation also induces the expression of p21 protein (inhibitor of cyclin-dependent kinase 1A). Its level is increased 1 and 3 days after irradiation and than it goes back to the control level (Fig. 4A). These results correlate with upregulated expression of its gene CDKN1A, which has the maximum in 3 days after irradiation (Fig. 4B). By using quantitative ELISA method we found that increase in p21 protein is dosedependent (Fig. 4C).

In the cells irradiated by 20 Gy senescence associated DNA-damage foci of $\gamma \mathrm{H} 2 \mathrm{AX}$ persisted in nuclei for 13 days (Fig. 5B). After p16 immunostaining we found out that the expression of p16 (inhibitor of cyclin-dependent kinase 2A), which is associated with cellular senescence, increases in day 13 post irradiation
(Fig. 5D).

We detected enhanced activity of senescenceassociated beta-galactosidase already on the first day after the irradiation with the dose of $20 \mathrm{~Gy}$ and its activity progressively increasing till day 13 (Fig. 5C).

\section{Discussion}

It is known that cellular response to ionizing radiation-induced damage depends on the cell type and the ability to repair DNA damage. In normal human skin fibroblasts irradiated by 6 Gy apoptosis induction is minimal, but 3 or more DNA damage foci persist $48 \mathrm{~h}$ and cell cycle is arrested, primarily in G1 phase, and the cells stop proliferation (Dimitrijevic-Bussod et al. 1999, Toussaint et al. 2000, Tsuboi et al. 2007). On the other hand, $48 \mathrm{~h}$ after the irradiation most of the cells of human 


\section{B}
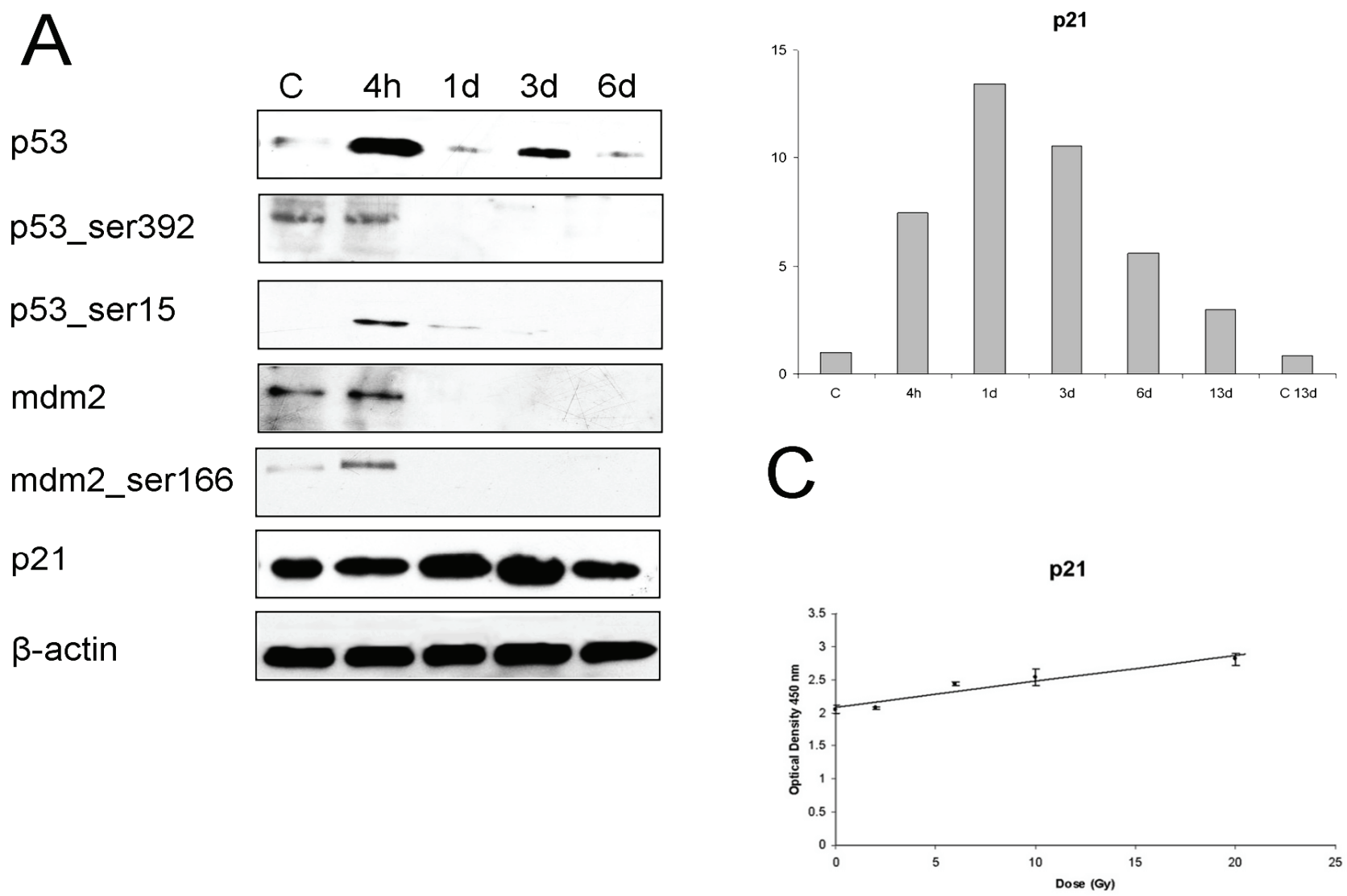

Fig. 4. Induction and activation of proteins in WI-38 cells after irradiation. A: WI-38 cells were irradiated with the dose of 20 Gy. Using electrophoresis and western blotting we evaluated changes in p53 and its phosphorylations at serines 15 and 392 , mdm2 protein and its phosphorylation at serine 166 and p21 protein. To confirm equal protein loading, membranes were reincubated with $\beta$-actin. B: The expression of genes for p21 was measured by using quantitative RT-PCR after the irradiation with the dose of 20 Gy during the interval of 13 days. The results of RT-PCR are in arbitrary units. C: Dose dependence of changes in p21 protein over the doses 2-20 Gy after 3 days post irradiation in WI-38 cells.

leukemia cell line MOLT-4 die by apoptosis, but $80 \%$ of the surviving cells repaired the damage and do not contain DNA-damage foci (Rezacova et al. 2008).

WI-38 cell line is derived from embryonic lung fibroblasts, and their response to irradiation differs from the response of normal skin fibroblasts. By using a comet assay we confirmed high amount of DNA damage induced by the irradiation, however the cells were able to repair single-strand breaks proficiently within 24 hours post irradiation and the percentage of DNA in comet tail quickly decreased. After irradiation a decrease in cell viability was observed in WI-38 cells, as well as weak induction of apoptosis, but more than half of the cells with remained viable even after irradiation by the dose of 20 Gy. Through the use of cell cycle analysis we detected significant amount of cells arrested in G2 phase (approx. $40 \%$ in day 1 and $30 \%$ in day 3). Our findings are in agreement with the work of Filion et al. (2009), who found in human embryonic stem cells that these cells lack a traditional restriction point in G1 and with work of Muthna et al. (2010), who detected similar cell cycle arrest in irradiated stem cells isolated from dental pulp. These findings are distinct from that observed in normal somatic cells (Filion et al. 2009).

Analysis of apoptosis induction revealed that there is no apoptosis induction till day 6 , when small increase in apoptotic cells is observed (10\% after $2 \mathrm{~Gy}$, $14.5 \%$ after 6 Gy and $10 \%$ after 20 Gy). This finding correlates with slight increase in activity of caspase $3 / 7$, 8 and 9 on 6 days after irradiation. In our previous study (Rezacova et al. 2008) a typical response of proliferating somatic cells to massive DNA damage caused by high doses of ionizing radiation was induction of apoptosis. Based on this investigation we used leukemic cell line 


\section{Control}

A

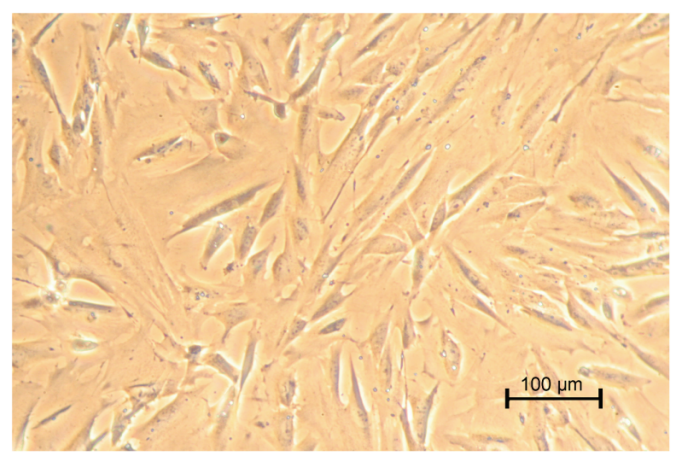

B

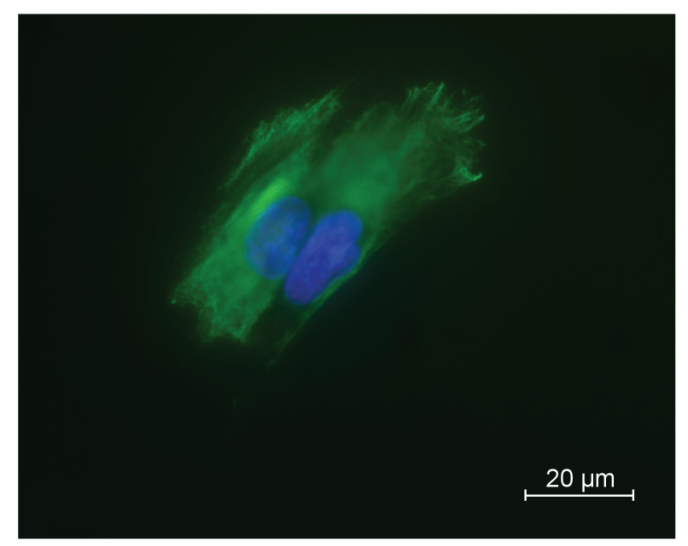

C

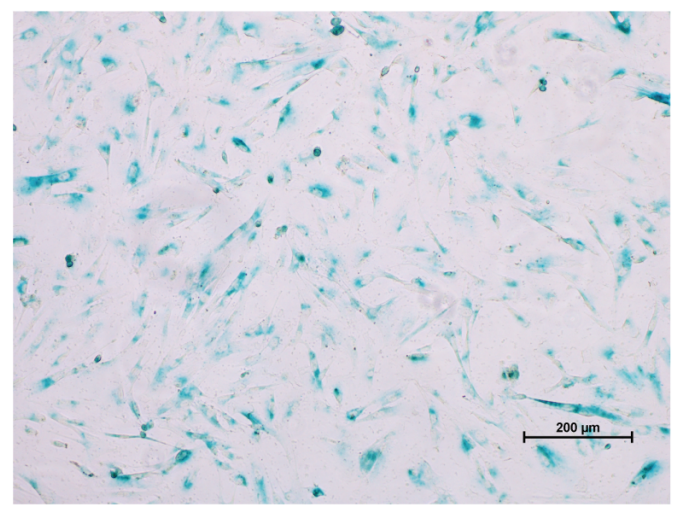

D

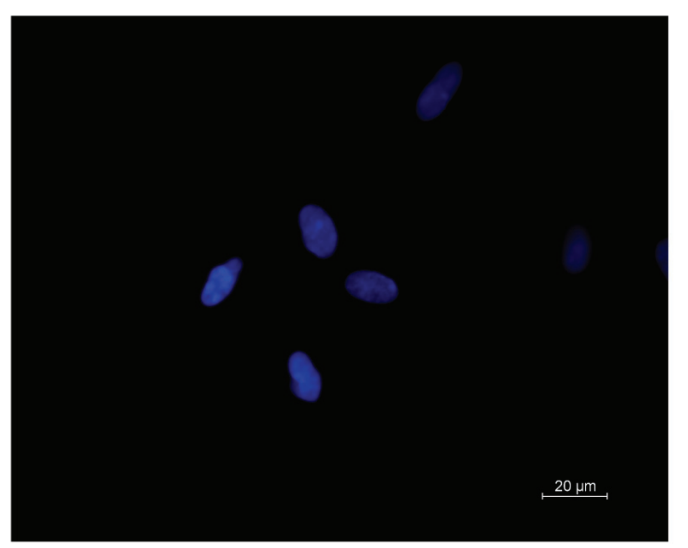

Day 13
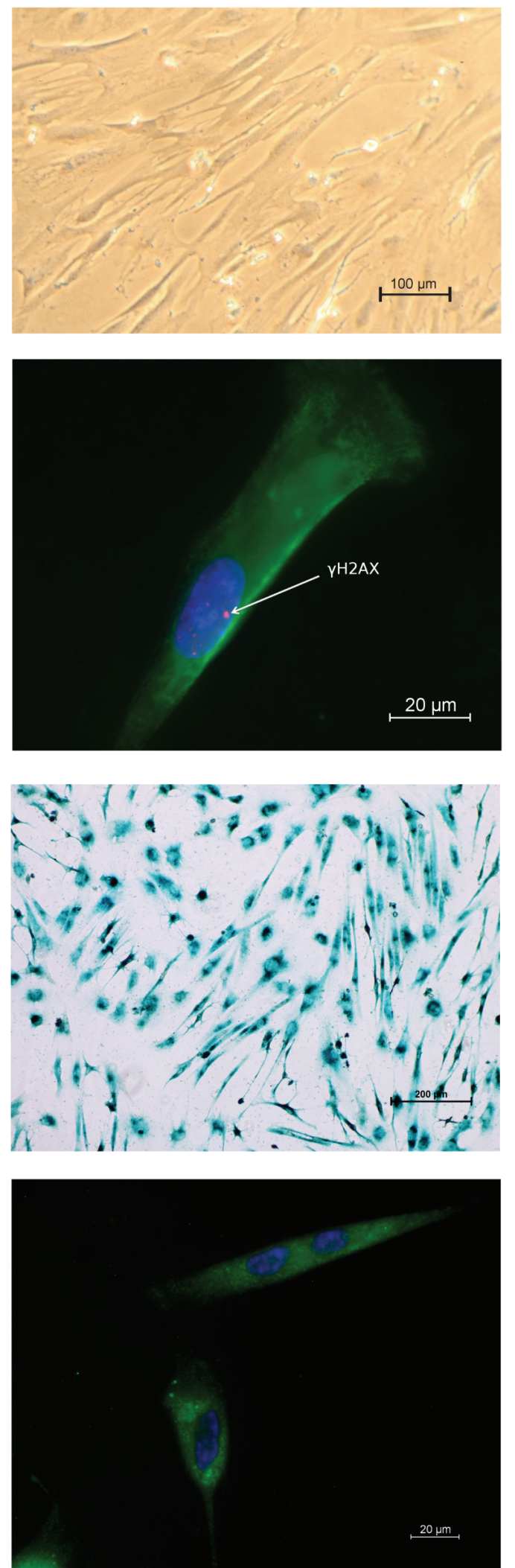

Fig. 5. The effect of irradiation in cell morphology and induction of senescence in WI-38 cells irradiated with the dose of $20 \mathrm{~Gy}$. A: Changes in cell morphology of WI-38 cells after the irradiation with the dose of 20 Gy after 13 days. B: Morphological changes and changes in nuclei were determined after 13 days after the irradiation with the dose 20 Gy. DAPI $+\gamma H 2 A X$ (red) + vimentin (green) staining. C: The cells were irradiated with the dose of $20 \mathrm{~Gy}$ in chamber slides and activity of senescence associated beta-galactosidase was detected histochemically after 13 days. D: Changes in expression p16 protein were determined after 13 days after the irradiation with the dose $20 \mathrm{~Gy}$. 
MOLT-4 as a positive control, where all of cells die by apoptosis $24 \mathrm{~h}$ after the irradiation with the dose of $3 \mathrm{~Gy}$. In comparison with this leukemic cell line the increase of caspases activity in WI-38 cells is not so marked (activity of caspases in MOLT_ 4 cell line are approximately ten times higher).

In this study we have shown that p53 is quickly activated and phosphorylated on serine 15 and serine 392 in WI-38 embryonic diploid fibroblasts in response to ionizing radiation. One of the most serious types of radiation-inuced DNA damage are double strand breaks of DNA. The first response of the cell to this type of DNA damage is the activation of ATM kinase by its autophosphorylation (Bakkenist and Kastan 2003). An important substrate of ATM kinase is the protein p53, which is phosphorylated and activated by ATM. ATM kinase phosphorylates protein p53 in the area, where mdm 2 protein is bound, most often on serine 15 . That is why the affinity of p53 to mdm 2 is decreased and p53 is not degraded. Phosphorylation on serine 392 increases the association constant for tetramer formation of protein p53 and can support the interaction with specific DNA sequences (Canman et al. 1998).

One downstream target of the p53 pathway is $C D K N 1 A$, gene encoding protein $\mathrm{p} 21^{\text {Cip1/Waf1 }}$. This protein belongs to the $\mathrm{Cdk} 2$ and $\mathrm{Cdk} 4$ inhibitors and induces cell cycle arrest. We found in our work that increased expression of p53 is followed by increase of protein p21, which is the typical response to genotoxic stress ( $\mathrm{Ju}$ et al. 2007).

What happened with WI-38 cells surviving the irradiation? In our study we have found increased expression of protein $\mathrm{p} 16^{\mathrm{INK} 4 \mathrm{a}}$ in surviving cells 13 days post irradiation by the dose of $20 \mathrm{~Gy}$. Tumor suppressor with protein $\mathrm{p} 16^{\mathrm{INK} 4 \mathrm{a}}$ is the crucial protein for induction of senescence (Suzuki and Boothman 2008). Ionizing radiation-triggered accelerated senescence strongly correlates with expression of $\mathrm{p} 16^{\mathrm{INK} 4 \mathrm{a}}$ and $\mathrm{p} 16^{\mathrm{INK} 4 \mathrm{a}}$ protects human fibroblasts from undergoing apoptosis in response to DNA damage (Mirzayans et al. 2009). Protein $\mathrm{p} 16^{\mathrm{INK} 4 \mathrm{a}}$ inhibits the activity of $\mathrm{Cdk} 4$ and Cdk6 kinases and induces hypophosphorylation of $\mathrm{Rb}$ protein. When $\mathrm{Rb}$ is in a hypophosphorylated state it is fully active and can block cell cycle progression by interacting with E2F to repress genes involved in cell cycle progression (Delston and Harbour 2006). One of others known markers of senescence is the presence of senescence-associated DNA-damage foci containing proteins that are associated with DNA damage recognition and repair, such as phosphorylated histone $\mathrm{H} 2 \mathrm{AX}-\gamma \mathrm{H} 2 \mathrm{AX}$ (Campisi et al. 2007) in the nucleus. After $\gamma \mathrm{H} 2 \mathrm{AX}$ staining we observed these foci in nuclei 13 days after the irradiation with 20 Gy. Other important marker of senescence is insreased beta-galactosidase activity (Eriksson and Stigbrand 2010). Betagalactosidase is a hydrolase enzyme, which is highly expressed and accumulated in lysosomes in senescent cells. We detected increased activity of senescenceassociated beta-galactosidase from the first day after irradiation, with maximum after 13 days. More recent studies have reported a similar observation. Suzuki et al. (2008) observed senescence-associated beta-galactosidase positive staining 3 days after the irradiation with the dose of $4 \mathrm{~Gy}$ in normal human diploid cells. The irradiation with the dose 2.5-15 Gy induces positive betagalactosidase staining in human mesenchymal stem cells in 10 days as well (Serakinci et al. 2007). Taken together our results indicate that the WI-38 human embryonic with fibroblasts surviving irradiation by the dose of $20 \mathrm{~Gy}$ enter stress-induced premature senescence.

Human embryonic diploid fibroblasts are frequently used for the study of cellular senescence (e.g. Lawless et al. 2010 used MRC-5 cell line, Raffetto et al. 2001 used WI-38 cell line). WI-38 also react by stressinduced prematured senescence after exposing cells at early passages to a single sub-cytotoxic dose of UVB (Straface et al. 2007) and to busulfan (an alkylating agent leading to DNA damage) (Probin et al. 2006).

In summary, our study demonstrates two types of response of embryonic diploid fibroblasts WI-38 to ionizing radiation. In the WI-38 cells p53 is activated, protein p21 increases, but the cells are arrested in G2 phase of cell cycle. Some of the cells die by apoptosis, but in remaining viable cells p16 increases, senescence associated DNA-damage foci occur, and senescenceassociated beta-galactosidase activity increases, which indicate stress-induced premature senescence.

\section{Conflict of Interest}

There is no conflict of interest.

\section{Acknowledgements}

This work was supported by Grant Agency of Czech Republic, project 304/09/1568.

\section{Abreviations}

ATM - ataxia telangiectasia mutated, BCA bicinchoninic acid, $\mathrm{Cdk}$ - cyclin dependent kinase, 
CDKN1A - inhibitor of cyclin-dependent kinase 1A, DAPI - 4'-6-diamidino-2-phenylindole, EDTA ethylenediaminetetraacetic acid, FITC - fluorescein isothiocyanate, Mdm2 - murine double minute protein,
PBS - phosphate Buffered Saline, PI - propidium iodide, PVDF - polyvinylidene difluoride, $\mathrm{Rb}$ - retinoblastoma protein, SDS - PAGE - sodium dodecyl sulphatepolyacrylamide gel electrophoresis.

\section{References}

BAKKENIST CHJ, KASTAN MB: DNA damage activates ATM through intermolecular autophosphorylation and dimer dissociation. Nature 421: 499-506, 2003.

BRINGOLD F, SERRANO M: Tumor suppressors and oncogenes in cellular senescence. Exp Gerontol 35: 317-329, 2000.

CAMPISI J, D'ADDA Di FAGAGNA F: Cellular senescence: when bad things happen to good cells. Nat Rev Mol Cell Biol 8: 729-740, 2007.

CANMAN CE, LIM DS, CIMPRICH KA, TAYA Y, TAMAI K, SAKAGUCHI K, APPELLA E, KASTAN M, SILICIANO JD: Activation of the ATM kinase by ionizing radiation and phosphorylation of p53. Science 281: 1677-1679, 1998.

DELSTON RB, HARBOUR JW: Rb at the interface between cell cycle and apoptotic decisions. Curr Mol Med 6: 713$718,2006$.

DIMITRIJEVIC-BUSSOD M, BALZARETTI-MAGGI VS, GADBOIS DM: Extracellular matrix and radiation G1 cell cycle arrest in human fibroblasts. Cancer Res 59: 4843-4847, 1999.

ERIKSSON D, STIGBRAND T: Radiation-induced cell death mechanisms. Tumor Biol 31: 363-372, 2010.

FILION TM, QIAO M, GHULE PN, MANDEVILLE M, VAN WIJNEN AJ, STEIN JL, LIAN JB, ALTIERI DC, STEIN G: Survival Responses of Human Embryonic Stem Cells to DNA Damage. J Cell Physiol 220: 586$592,2009$.

JU Z, CHOUDHURY AR, RUDOLPH KL: A dual role of p21 in stem cell aging. Ann N Y Acad Sci 1100: $333-344$, 2007.

LAWLESS C, WANG C, JURK D, MERZ A, ZGLINICKI T, PASSOS JF: Quantitative assessment of markers for cell senescence. Exp Gerontol 45: 772-778, 2010.

LJUNGMAN M: Dial 9-1-1 for p53: Mechanisms of p53 activation by cellular stress. Neoplasia 2: 208-225, 2000.

MENG A, WANG Y, ZANT GV, ZHOU D: Ionizing radiation and busulfan induce premature senescence in murine bone marrow hematopoietic cells. Cancer Res 63: 5414-5419, 2003.

MUTHNA D, SOUKUP T, VAVROVA J, MOKRY J, CMIELOVA J, VISEK B, JIROUTOVA A, HAVELEK R, SUCHANEK J, FILIP S, ENGLISH D, REZACOVA M: Irradiation of adult human dental pulp stem cells provokes activation of p53, cell cycle arrest and senescence but not apoptosis. Stem Cells Dev 19: 1855-1862, 2010.

MIRZAYANS R, ANDRAIS B, SCOTT A, PATERSON MC, MURRAY D: Single-cell analysis of p16 ${ }^{\mathrm{INK} 4 \mathrm{a}}$ and $\mathrm{p} 21^{\mathrm{WAF} 1}$ expression suggests distinct mechanisms of senescence in normal human and Li-Fraumeni Syndrome fibroblasts. J Cell Physiol 223: 57-67, 2010.

PROBIN V, WANG Y, ZHOU D: Busulfan-induced senescence is dependent on ROS production upstream of the MAPK pathway. Free Radic Biol Med 42: 1858-1865, 2007.

RAFFETTO JD, LEVERKUS M, PARK HY, MENZOIAN JO: Synopsis on cellular senescence and apoptosis. $J$ Vasc Surg 34: 173-177, 2001.

REZACOVA M, TICHY A, VAVROVA J, VOKURKOVA D, LUKASOVA E: Is defect in phosphorylation of Nbs1 responsible for high radiosensitivity of T-lymphocyte leukemia cells MOLT-4? Leuk Res 32: 1259-1267, 2008.

REZACOVA M, VAVROVA J, VOKURKOVA D: Ionizing radiation sensitizes leukemic MOLT-4 cells trail-induced apoptosis. Acta Medica 51: 101-105, 2008.

SERAKINCI N, CHRISTENSEN R, GRAAKJAER J: Ectopically hTERT expressing adult human mesenchymal stem cells are less radiosensitive than their telomerase negative counterpart. Exp Cell Res 313: 1056-1067, 2007. 
STRAFACE E, VONA R, ASCIONE B, MATARRESE P, STRUDTHOFF T, FRANCONI F, MALORNI W: Single exposure of human fibroblasts (WI-38) to a sub-cytotoxic dose of UVB induces premature senescence. FEBS Letters 581: 4342-4348, 2007.

SUZUKI M, BOOTHMAN DA: Stress-induced premature senescence (SIPS). J Radiat Res 49: 105-112, 2008.

TAYLOR WR, STARK GR: Regulation of the G2/M transition by p53. Oncogene 20: 1803-1815, 2001.

TOUSSAINT O, MEDRANO EE, ZGLINICKI T: Cellular and molecular mechanisms of stress-induced premature senescence (SIPS) of human diploid fibroblasts and melanocytes. Exp Gerontol 35: 927-945, 2000.

TSUBOI K, MORITAKE T, TSUCHIDA Y, TOKUUYE K, MATSUMURA A, ANDO K: Cell cycle checkpoint and apoptosis induction in glioblastoma cells and fibroblasts irradiated with carbon beam. J Radiat Res (Tokyo) 48 : 317-325, 2007.

VÁVROVÁ J, VOKURKOVÁ D, MAREKOVÁ M, BLÁHA M, JEBAVÝ L, FILIP S: Antiapoptotic cytokine IL-3 + SCF + FLT3L influence on proliferation of gamma-irradiated AC133+/CD34+ progenitor cells. Folia Biol (Praha) 48: 51-57, 2002. 